\title{
Good as 'gold'? Portable sleep study devices for sleep-disordered breathing in children
}

\author{
Evelyn Constantin MD MSc(Epi)
}

$\mathrm{I}^{\mathrm{n}}$ $\mathrm{n}$ the current issue of the Canadian Respiratory Journal, Massicotte et al (1) (pages 31-35) compared the ApneaLink (AL) monitor (ResMed, USA), a portable sleep study (PSS) device (PSS-AL), to gold-standard polysomnography (PSG) in children with suspected sleep-disordered breathing (SDB) referred to a tertiary care centre. The authors hypothesized that the PSS-AL could help identify children with moderate-severe SDB. This is the first study to evaluate the PSS-AL in younger children. The authors compared PSG apneahypopnea index (AHI) with PSS-AL data in 35 children (four to 17 years of age; median age 11 years). As the authors hypothesized, the PSS-AL was able to identify children with moderate-severe SDB on PSG (AHI $\geq 5$ ). Sensitivity was $100 \%$; however, specificity was low $(40 \%)$. Notably, these values were based on data from only five children with moderate-severe SDB on PSG. Moreover, while the PSS-AL correctly identified these five children, the PSS-AL unfortunately misclassified 18 other children as having moderate-severe SDB. Additionally, while 18 children had normal PSG, the PSS-AL only identified four with an $\mathrm{AHI}<1.5$.

Although PSG is a detailed and well-accepted tool for diagnosis of $\mathrm{SDB}$, it is labour-intensive, requires specialized expertise and is costly. In Canada, sleep laboratory resources are limited and referral numbers are high, leading to long wait times. To address this clinical need under limited health care resources, some groups have evaluated PSS devices. Such devices would need to be comparable with PSG, accurate, safe and cost effective. A recent meta-analysis (2) reported that PSS devices, compared with PSG, had high sensitivity and specificity to diagnose obstructive sleep apnea (OSA) in adults without significant comorbidities and who had a high pretest probability of moderatesevere OSA. However, they noted that PSG remains the gold standard for adults with suspected or at risk for other sleep disorders. A Canadian position paper reported that portable monitoring is useful (particularly in expediting treatment) in adults with high clinical suspicion of OSA and emphasized that portable monitoring should be used "appropriately under the supervision of a physician with training in sleep medicine, and in conjunction with a comprehensive sleep evaluation" (3).

Several comparison studies involving children have been conducted (4-7). In 1995, Jacob et al (4) compared a PSS system with PSG and showed that the PSS had a high sensitivity for detecting OSA. This system, however, was complex, not easily portable and required a specialized technician for home set-up. Poels et al (5) compared a different PSS device (set-up by a family member) with PSG. Unfortunately, most of the recordings were not successful and technically not acceptable. Brouillette et al (6) validated nocturnal home oximetry in children referred for suspected OSA. The technical failure rate was low and abnormal oximetry was shown to have a positive predictive value of $97 \%$ at detecting OSA when compared with PSG. However, oximetry had low sensitivity and low negative predictive values. Children who had inconclusive oximetry findings (OSA could not be ruled out) would require PSG for further evaluation for SDB.

The product brochure for ApneaLink states that it is a "simple, costeffective sleep-screening tool" (www.resmed.com). Massicotte et al (1) also report that the PSS-AL, used in conjunction with a clinical evaluation by a specialized clinician, can be considered a tool to help screen children for SDB and triage for further testing. Thus, this device is not being promoted as a diagnostic tool for OSA or central sleep apnea (CSA) in children, and should not replace laboratory PSG.

The study by Massicotte et al (1) is a valuable contribution to the existing literature on PSS devices for children. This study is important and relevant because it examines an alternative method of screening and triaging children with suspected SDB in the high-need, lowresource setting of the Canadian health care system. It is the first study to examine this particular device - the ApneaLink monitor - in younger children. This particular PSS device, however, has some inherent and critical limitations. First and foremost, it cannot distinguish between obstructive and central apnea events because only nasal airflow is measured. This limitation is of particular importance because almost $15 \%$ of children in the study had comorbidities that may place them at higher risk for CSA (Chiari malformation, central nervous system tumours). Also noteworthy, the median central apnea index on PSG was low (0.1), yet there were children in this study with central apnea indexes as high as 9.7. It is unclear how many children with CSA would have been misclassified using the PSS-AL.

The feasibility of PSS in the home setting is also of concern. Forty per cent were excluded due to limited recording time or insufficient flow signal. These technical issues were frequent considering that the PSS-AL was trialed in the laboratory setting. Would the failure rate be higher in the home setting? Furthermore, PSS devices used in unsupervised settings in the home may be unsafe due to risk of strangulation from nasal flow signal wires around the face and neck (8-10).

Presently, PSS devices are not standard of care for clinical use in children for diagnosis of OSA or CSA. The study by Massicotte et al (1) has highlighted potential advantages of this tool for the screening and triaging of children with suspected SDB. However, before promoting its use in clinical practice, diagnostic and other limitations of this and other PSS devices need to be strongly considered. Moreover, of major concern are the issues of technical feasibility in the home and potential risks in an unsupervised setting, particularly with younger children.

\section{REFERENCES}

1. Massicotte C, Al-Saleh S, Witmans M, Narang I. The utlility of a portable sleep monitor to diagnose sleep-disordered breathing in a pediatric population. Can Respir J 2014:21:31-5.

2. El Shayeb ME, Topfer LA, Stafinski T, Pawluk L, Menon D. Diagnostic accuracy of level 3 portable sleep tests versus level 1 polysomnography for sleep-disordered breathing: A systematic review and meta-analysis. CMAJ 2014;186:E25-51.

3. Canadian Sleep Society, Blackman A, McGregor C, Dales R, et al; Canadian Thoracic Society, Fleetham JA, Ayas N, Bradley TD, et al. Canadian Sleep Society/Canadian Thoracic Society position paper on the use of portable monitoring for the diagnosis of obstructive sleep apnea/hypopnea in adults. Can Respir J 2010;17:229-32. 
4. Jacob S, Morielli A, Mograss M, Ducharme F, Schloss M, Brouillette R. Home testing for pediatric obstructive sleep apnea syndrome secondary to adenotonsillar hypertrophy. Pediatr Pulmonol 1995;20:241-52.

5. Poels PJ, Schilder AG, van den BS, Hoes AW, Joosten KF. Evaluation of a new device for home cardiorespiratory recording in children. Arch Otolaryngol Head Neck Surg 2003;129:1281-4.

6. Brouillette RT, Morielli A, Leimanis A, Waters KA, Luciano R, Ducharme FM. Nocturnal pulse oximetry as an abbreviated testing modality for pediatric obstructive sleep apnea.

Pediatrics 2000;105:405-12.

7. Nixon GM, Kermack AS, Davis GM, Manoukian JJ, Brown KA, Brouillette RT. Planning adenotonsillectomy in children with obstructive sleep apnea: The role of overnight oximetry. Pediatrics 2004;113:e19-e25.

8. Emery JL, Taylor EM, Carpenter RG, Waite AJ. Apnea monitors and accidental strangulation. BMJ 1992;304:117.

9. Health Canada, Health Products and Food Branch. Notice to Hospitals: Risk of strangulation of infants by IV Tubing and Monitor Leads. <http://healthycanadians.gc.ca/recall-alert-rappelavis/hc-sc/2003/14222a-eng.php> (Accessed November 26, 2013).

10. Garros D, King WJ, Brady-Fryer B, Klassen TP. Strangulation with intravenous tubing: A previously undescribed adverse advent in children. Pediatrics 2003;111:e732-e734<http://pediatrics. aappublications.org/cgi/content/full/111/6/e732> (Accessed November 26, 2013). 


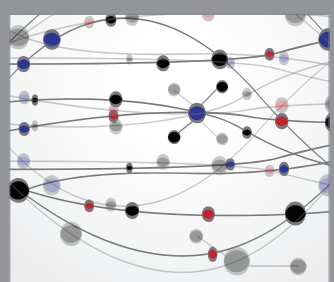

The Scientific World Journal
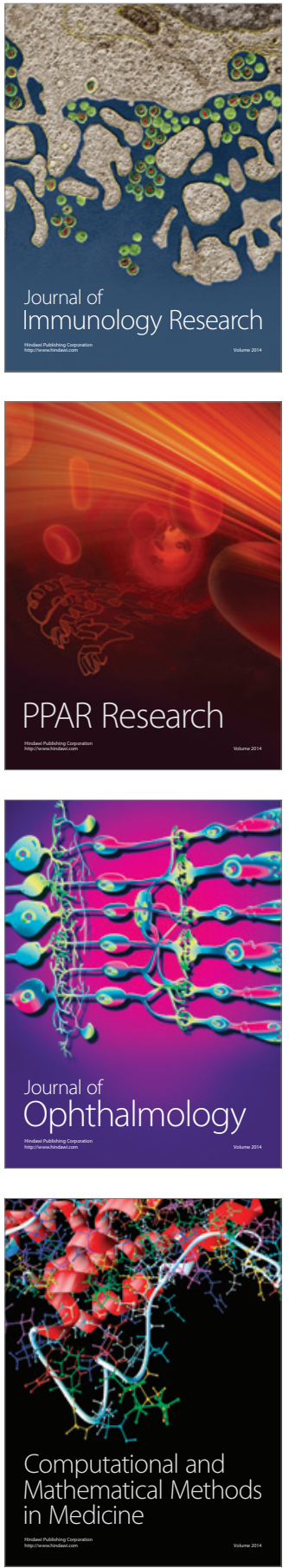

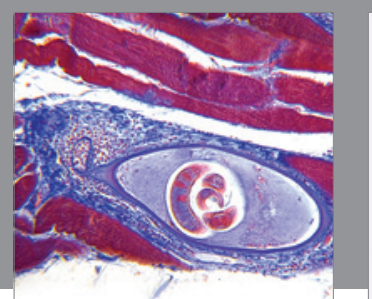

Gastroenterology Research and Practice

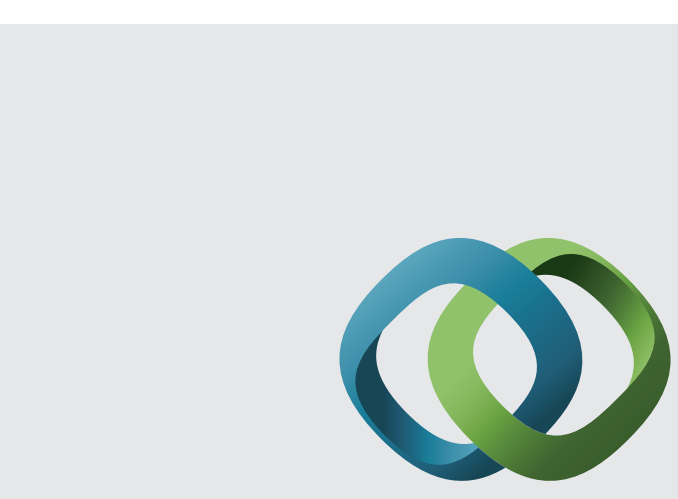

\section{Hindawi}

Submit your manuscripts at

http://www.hindawi.com
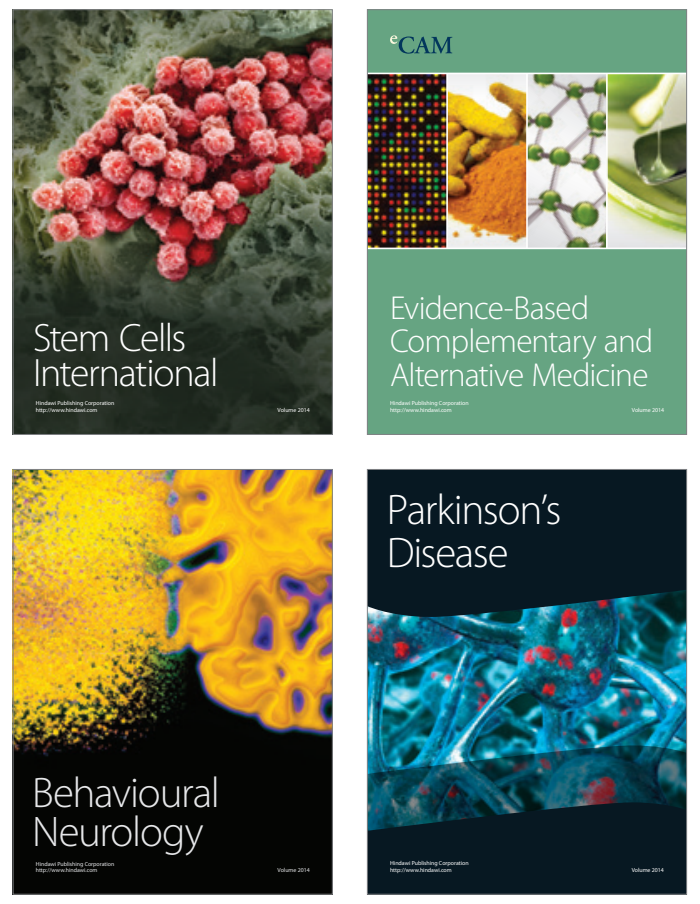
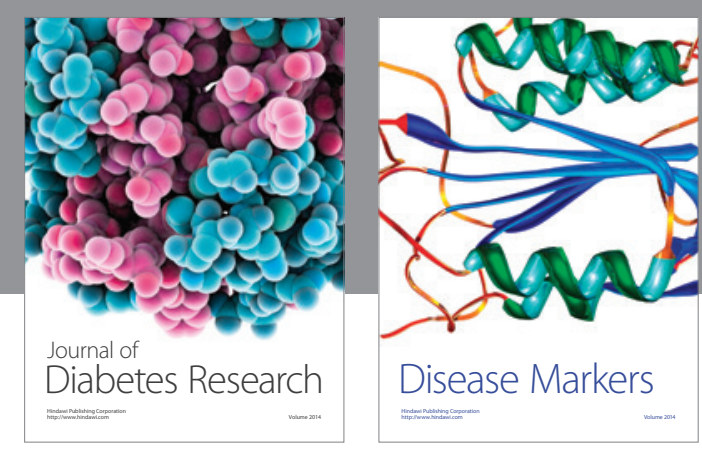

Disease Markers
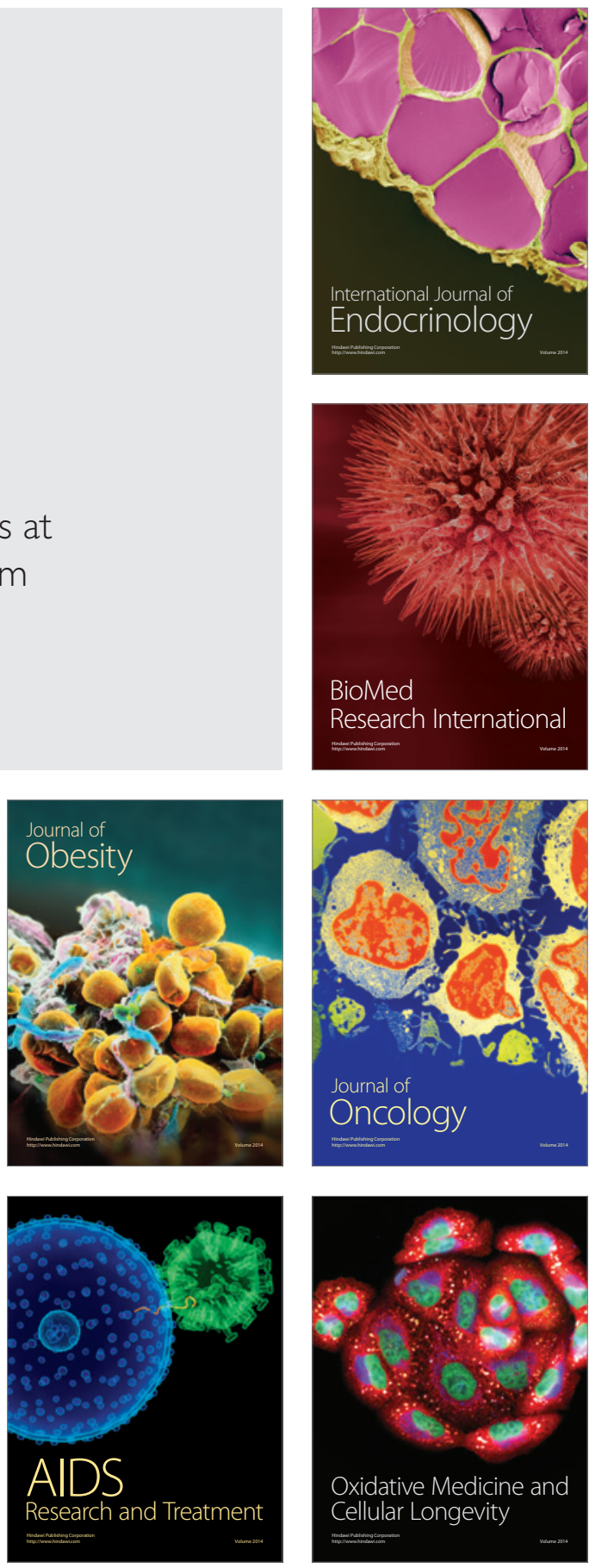